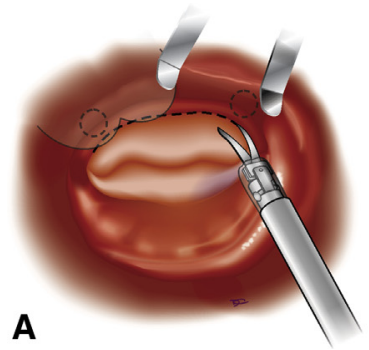

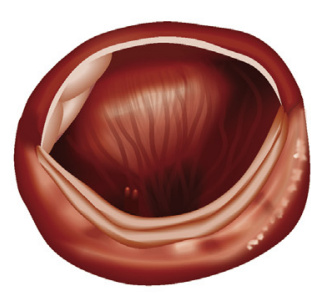

B

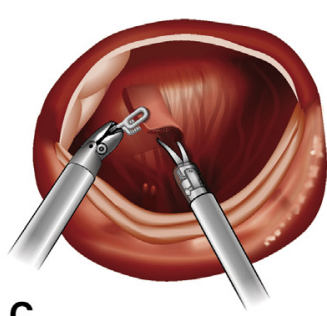

C

FIGURE 1. A, Opening the mitral valve anterior leaflet. Curved robotic scissors were used to incise the anterior leaflet, proceeding counterclockwise in a radial fashion from the right fibrous trigone to the left fibrous trigone. B, Exposure of the interventricular septum and aortic valve through the mobilized mitral valve anterior leaflet. C, Resection of the previously ablated fibrotic interventricular septum. The rectangular resected tissue was extended clockwise from near the left fibrous trigone to the nadir of the right coronary cusp.

\section{DISCUSSION}

The Morrow procedure uses a midline sternotomy, with the left ventricle and septum accessed by the aortic valve through a vertical aortotomy. ${ }^{4}$ The potential limitations of the procedure include small, but persistent, risks of an aortotomy (eg, postoperative bleeding, aortic dissection), difficulties with visualizing the surgical anatomy, and the risk of aortic valve damage (approximately $5 \%$ rate of moderate aortic regurgitation postoperatively ${ }^{5}$ ).

A robotic approach using the left atrium and across the mitral valve is an alternative and more direct route to the ventricular septum that can circumvent the limitations of the standard transaortic approach. The required robotic manipulation of the mitral valve for left ventricular septum access seems less risky than the transaortic route across the often friable aortic valve for provoking valvular damage.

Although additional studies are needed to evaluate the frequency of associated complications, our robot-assisted technique could be an acceptable alternative to the Morrow procedure.

The authors would like to thank Michael F. Teodori, MD, for surgical guidance in the operating room. Additional thanks are given to Katherine Stavoe and Kitsie Penick for assistance with manuscript preparation.

\section{References}

1. Maron BJ, Maron MS. Hypertrophic cardiomyopathy. Lancet. 2013;381:242-55.

2. Agarwal S, Tuzcu EM, Desai MY, Smedira N, Lever HM, Lytle BW, et al. Updated meta-analysis of septal alcohol ablation versus myectomy for hypertrophic cardiomyopathy. J Am Coll Cardiol. 2010;55:823-34.

3. Chitwood WR. Idiopathic hypertrophic septal obstruction: robotic transatrial and transmitral ventricular septal resection. Oper Tech Thorac Cardiovasc Surg. 2012; 17:251-60.

4. Morrow AG, Reitz BA, Epstein SE, Henry WL, Conkle DM, et al. Operative treatment in hypertrophic subaortic stenosis: techniques, and the results of pre and postoperative assessments in 83 patients. Circulation. 1975;52:88-102.

5. van der Linde D, Roos-Hesselink JW, Rizopoulos D, Heuvelman HJ, Budts W, van Dijk AP, et al. Surgical outcome of discrete subaortic stenosis in adults: a multicenter study. Circulation. 2013;127:1184-91.

\title{
Modified surgical approach to symptomatic hypertrophic cardiomyopathy with abnormal papillary muscle morphology: Septal myectomy plus papillary muscle repositioning
}

\author{
Marianna Redaelli, MD, Camillo Luca Poloni, MD, Samuele Bichi, MD, and Giampiero Esposito, MD, \\ Bergamo, Italy
}

\footnotetext{
From the Section of Cardiac Surgery, Department of Cardiovascular Disease, Cliniche Humanitas Gavazzeni, Bergamo, Italy.

Disclosures: Authors have nothing to disclose with regard to commercial support.

Received for publication May 3, 2013; revisions received Sept 27, 2013; accepted for publication Oct 6, 2013; available ahead of print Feb 9, 2014.

Address for reprints: Marianna Redaelli, MD, Istituto Clinico Humanitas Gavazzeni, via mauro Gavazzeni, Bergamo 24125, Italy (E-mail: marianna.redaelli@ gavazzeni.it).

J Thorac Cardiovasc Surg 2014;147:1709-11

$0022-5223 / \$ 36.00$

Copyright (c) 2014 by The American Association for Thoracic Surgery

http://dx.doi.org/10.1016/j.jtcvs.2013.10.085
}

Hypertrophic obstructive cardiomyopathy (HOCM) is considered a primary disease of cardiac muscle characterized by a diverse morphologic and clinical spectrum. ${ }^{1,2}$ The physiopathology of hypertrophic cardiomyopathy has been clarified by advanced echocardiographic and magnetic resonance imaging technologies (cardiac magnetic resonance imaging). With these advances, surgical management has also evolved, because the role of the mitral valve and subvalvular structures in causing 
TABLE 1. Clinical and morphologic features for 15 patients with HOCM due to anomalous papillary muscle insertion

\begin{tabular}{|c|c|}
\hline Parameter & Value \\
\hline Median age (y) & 61 \\
\hline \multicolumn{2}{|l|}{ NYHA functional class } \\
\hline \multicolumn{2}{|l|}{ Preoperative } \\
\hline Class III & 9 \\
\hline Class II & 6 \\
\hline Postoperative, class I & 15 \\
\hline \multicolumn{2}{|l|}{ Gender } \\
\hline Male & 5 \\
\hline Female & 10 \\
\hline \multicolumn{2}{|l|}{ Basal LVOTG (mm Hg) } \\
\hline \multicolumn{2}{|l|}{ Preoperative } \\
\hline Minimum & 40 \\
\hline Peak & 63 \\
\hline \multicolumn{2}{|l|}{ Postoperative } \\
\hline Range & $0-18$ \\
\hline Median & 10 \\
\hline \multicolumn{2}{|l|}{ SAM } \\
\hline Preoperative & 15 \\
\hline Postoperative & 0 \\
\hline \multicolumn{2}{|l|}{ Mitral regurgitation } \\
\hline \multicolumn{2}{|l|}{ Preoperative } \\
\hline Moderate & 7 \\
\hline Mild & 8 \\
\hline \multicolumn{2}{|l|}{ Postoperative } \\
\hline No gradient & 11 \\
\hline Mild & 4 \\
\hline Preoperative LV wall thickness, anterior septum (mm) & 23 \\
\hline Postoperative LV wall thickness, anterior septum (mm) & $12-15$ \\
\hline
\end{tabular}

obstruction has been clarified. A recent study has demonstrated that abnormal papillary muscle morphology was associated with dynamic left ventricular outflow tract (LVOT) obstruction, independent of the basal septal thickness. $^{3}$

The most common cause of obstruction is contact between anterior leaflet of the mitral valve and hypertrophied septum, commonly know as systolic anterior motion (SAM). In a subset of patients with HOCM, LVOT obstruction will be present in the midcavity region owing to muscular apposition created by abnormal papillary muscle morphology. Failure to recognize this anomaly can have catastrophic consequences during surgery, because the standard myotomy and myectomy will not relieve the obstruction. ${ }^{4}$

We report the baseline characteristics and short-term outcomes of patients with HOCM who had undergone septal myectomy plus anterior papillary muscle repositioning.

\section{METHODS}

From January 2002 to January 2012, 98 patients with HOCM were referred for surgical intervention for symptomatic LVOT obstruction after
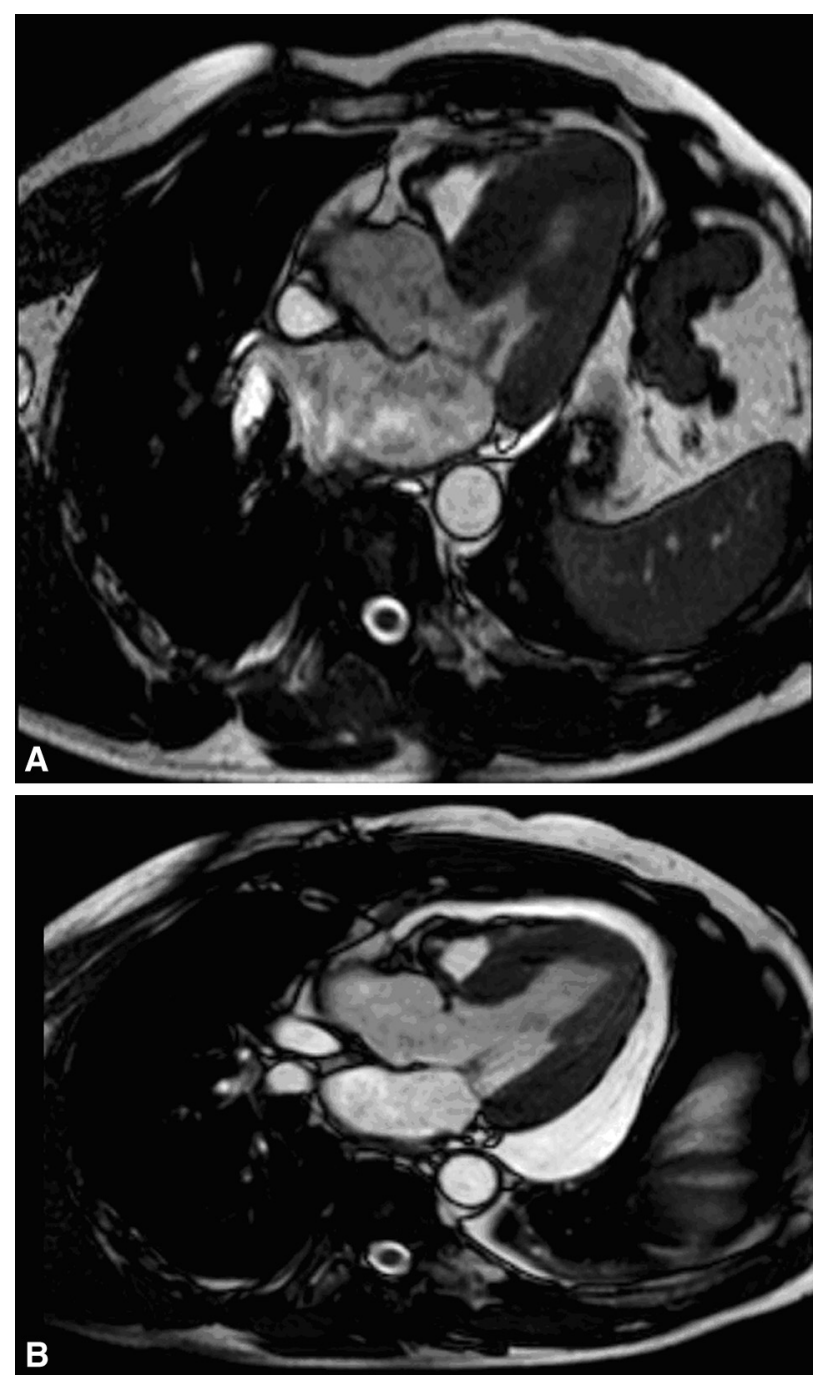

FIGURE 1. Computed tomography scans showing (A) an obstructed outflow tract (preoperative image) and (B) a wide outflow (postoperative image).

undergoing a comprehensive clinical, electrocardiographic, and imaging evaluation. Of these 98 patients, 15 presented with abnormal papillary muscle morphology (Table 1). In this subgroup of HOCM, an innovative surgical strategy was applied. The institutional review board approved the study. The requirement for patient consent was waived.

Our alternative subvalvular surgical solution in treating complex HOCM with SAM included extensive myectomy plus repositioning of the anterior papillary muscle and excision of the accessory papillary muscle and chords. This procedure was completed by implantation of a complete semirigid ring (Memo 3D, Sorin, Saluggia, Italy).

\section{SURGICAL TECHNIQUE}

Through standard median sternotomy, the cardiopulmonary bypass was instituted by cannulating the ascending aorta and right atrium with a single 2-stage cannula. After aortic crossclamping, the crystalloid cardioplegia solution (Custodiol HTK solution; Koehler Chemie, Alsbach-Haenlein, Germany) was administered in the aortic root. 
The surgical analysis was performed using a transaortic approach. The presence of an altered morphology of the anterior papillary muscle was then confirmed. The adequate septal myectomy was performed as a first step by way of the aortic valve, with rectangular muscular resection from the nadir of the right coronary cusp into the midventricular region to the level of the attachments of the anomalous anterior papillary muscle (Morrow procedure).

In the presence of muscular midcavity obstruction owing to an anomalous papillary muscle, standard myectomy was combined with repositioning of the anterior papillary muscle approached by way of the left atrial roof ${ }^{5}$ (second step). This procedure was performed with an incision between the anterior and medium branch of the anterior papillary muscle and union of its anterior and posterior branch with 4-0 polypropylene suture, with interposition of a small autologous pericardial patch to avoid muscle damage.

In the third step, a complete, semirigid ring (Memo 3D, Sorin, Saluggia, Italy) was implanted.

\section{RESULTS}

No deaths at 30 postoperative days were observed. Postoperative transthoracic echocardiography and cardiac magnetic resonance imaging showed no residual gradient superior to $18 \mathrm{~mm} \mathrm{Hg}$. The patients were in New York Heart Association class I during the follow-up period. All the patients were in sinus rhythm. After surgery, the LVOT appeared to be widely patent throughout the cardiac cycle. SAM was abolished without residual mitral regurgitation in 11 patients and mild regurgitation in 4 patients.

\section{DISCUSSION}

HOCM was considered to be a disease mostly related to asymmetric septal hypertrophy. The main causes of obstruction were bulging of hypertrophied interventricular septum, indicating the presence of SAM. Other not so rare anatomic anomalies include elongation of the anterior leaflet, altered morphology of the anterior papillary muscle, and presence of abnormal subvalvular segments (accessory papillary muscles and chords).

The standard surgical technique has been the Morrow procedure for isolated septal hypertrophy. Nevertheless, an associated abnormal mitral valve and subvalvular apparatus are present, this approach will not be sufficient. For these reasons, other surgical procedures have been developed. In the decision making, one should consider that a significant proportion of patients will be young and that mitral valve replacement or surgical mitral leaflet manipulation will be undesirable. Our novel approach was directed toward the avoidance of a mitral valve lesion.

However, recent studies with cardiac magnetic resonance imaging have demonstrated a high frequency of papillary muscle abnormalities in patients with HCOM that will frequently be missed by echocardiographic analysis. $^{5}$

With our surgical strategy, a wide outflow tract was created by performing extended muscular resection well beyond the site of midventricular obstruction (Figure 1). Moreover, repositioning of the anterior papillary muscle, followed by adjunctive implantation of a complete semirigid mitral ring, has permitted the abolishment of the SAM effect and residual mitral regurgitation.

\section{CONCLUSIONS}

A tailored surgical approach in patients presenting with HOCM, with abnormal papillary muscle morphology, obtained optimal results in terms of gradient decrease and the elimination of symptoms. At short-term follow-up, all patients were asymptomatic and without need for reoperation. However, the long-term outcomes need to be ascertained.

\section{References}

1. Klues HG, Maron B, Dollar AL, Roberts WC. Diversity of structural mitral valve alterations in hypertrophic cardiomyopathy. Circulation. 1992;85:1651-60.

2. Maron BJ, Maron MS. Hypertrophic cardiomyopathy. Lancet. 2013;381: 242-55.

3. Kwon DH, Setser RM, Thamilarasan M, Popovic ZV, Smedira NG Schoenhagen P. Abnormal papillary muscle morphology is independently associated with increased left ventricular outflow tract obstruction in hypertrophic cardiomyopathy. Heart. 2008;94:1295-301.

4. Maron BJ, Nishimura RA, Danielson GK. Pitfalls in clinical recognition: a novel operative approach for hypertrophic cardiomyopathy with severe outflow tract obstruction due to anomalous papillary muscle. Circulation. 1998;98:2505-8.

5. Esposito G, Cappabianca G, Bichi S, Patrini D, Pellegrino P. Left atrial roof: an alternative minimal approach for mitral valve surgery. Innovations. 2012;7:417-20. 